\title{
Teat Stick Dosage Form
}

National Cancer Institute

\section{Source}

National Cancer Institute. Teat Stick Dosage Form. NCI Thesaurus. Code C149990.

Solid single-dose preparation for veterinary use, usually rod shaped, intended to be inserted into the teat canal of an animal where it melts or dissolves. 